\title{
A Sociolinguistic Study of Husband-to-Wife Address Forms and Functions in Rural Jordanian Community
}

\author{
Awni Shati M. Etaywe * \\ (Jordanian Association of Translators and Applied Linguists, Jordan)
}

\begin{abstract}
People in speech communities are unique, and so are their behaviours. This study aims at investigating how husbands coming from the northern rural Jordanian speech community address their wives when spouses are (not) alone, and for what functions. Data were collected from a purposive sample of husbands through a discourse completion task which focused on the use of address forms (AFs) as an entry point into situations of complaint, invitation, greeting and request. Data were categorized and analyzed qualitatively, and drawn upon Brown and Gilman's (1960) two-dimensional model and Hymes' $(1962,1964,1972)$ ethnography of (cultural) communication-approach. Results showed that husbands used 'teknonyms, epithets, forenames, zero form and endearment terms'. Results showed significant impact of relative academic background and length of marriage period on husbands' employment of AFs. AFs reflected stereotypic and cautious communication which showed that AFs in rural settings were not selected randomly, but rather for a practical value in managing spouse relationships. Laden with situationgoverned functions, AFs introduced a culturally distinctive system of ways to intelligently maintain the relative politeness, power, solidarity, status and intimacy relations, consistently with the socio-cultural context. This study provides implications for linguistic ethnography and further sociolinguistic research on AFs.
\end{abstract}

Keywords: form, function, sociocultural, politeness, power, solidarity

\section{Introduction}

In an attempt to systemize the conventional address forms (AFs) that identify the addressee (wife), the speaker (husband), and what social meanings, functions or attitudes they communicate in a certain socio-cultural context, this study explores the conventional

\footnotetext{
${ }^{*}$ Awni Shati M. Etaywe: A full member of the Jordanian Association of Translators and Applied Linguists (JATAL), which is a member of the International Association of Applied Linguistics (AILA). Etaywe has taught English in Jordan for several years. He has been the senior translator at Jordan Center for Strategic Studies and Lessons Learned, and an interpreter at multiple United Nations missions. His fields of interest include Forensic Linguistics, Pragmatics, Sociolinguistics and Discourse Analysis. E-mail: awnietaywe2@ gmail.com; awnietaywe2@hotmail.com.
} 


\section{A Sociolinguistic Study of Husband-to-Wife Address Forms and Functions \\ in Rural Jordanian Community}

AFs used in rural Jordanian areas by husbands from a sociolinguistic point of view. AFs are a common occurrence in everyday life and constitute one of the "most obvious way[s] in which the relationship between language and context is reflected" (Levinson, 1983:54). An $\mathrm{AF}$ is a word or phrase for the person being talked to (Yule, 2006). AFs are words or expressions used in interactive, dyadic and face-to-face situations to designate the person being talked to (Oyetade, 1995). Examining how "people use language [including AFs] in different social contexts provides a wealth of information about the way language works, as well as about the social relationships in a community" (Holmes, 1992:1). Being a word, phrase or an expression that designates the addressee, an AF once studied can reveal the relationship between its use and the context, and thus reflect social characteristics of the speakers and the social context that affect the language use.

Having said that, AFs present "a sociolinguistic subject par excellence" (Philipsen \& Huspek, 1985:94). People use AFs as useful means of building inter-personal interaction, and hence constituting a key part of verbal behaviour which mirrors people's s norms and practices in a particular society. Parkinson (1985:1) has stressed that AFs are important conveyors of social information and wealth of information. Therefore, AFs present an area of interest to well understand the link between language and society should we take into account that linguistic choices used to address people are influenced by such variables as age and sex, hence, investigating the impact of the situation and social variables on the used AFs is paramount. Hymes (1972), best known for his role in the ethnography of communication that describes an approach to understanding language in use, argues that situated data of speakers' communicative choices and their interpretation of these choices can enhance our understanding of the distinctive and complex systems of interpersonal relating that underlie daily interactions. For Hymes (1962, 1964), 'speech cannot be considered separate from the sociological and cultural factors that help shape linguistic forms and create meaning'; that is because 'speakers of a language in a particular community communicate with one another in a way that is appropriate to their sociocultural context'. Along this line of thought, I believe that decoding what AFs communicate is likely to be influenced by the 'speech situation' (socially contextual situation like meals, fights, etc.) and 'speech event' (Hymes, 1972:56) as well as the social and cultural variables which are, therefore, explored in this study.

Reviewing the literature in the context of Arabs' use of AFs, in general, and Jordanians', in particular, has revealed an absence of research dealing with 'husband-to-wife' AFs and social meanings or functions thereof. This gap was the impetus of this study which seeks to contribute towards adding to the existing literature through investigating AFs and functions as determined by social settings and when at the entrance of interactional events which include communicative acts of complaint, greeting, invitation and request. This highlights 
the value of a socio-pragmatic analysis of used AFs. Studying AFs used in certain events and situations can reveal valuable social information related to the interlocutors, place and time of the speech event (Parkinson, 1985:1). The significance of this study, therefore, lies in dealing with the influence of social variables and situational context on the choice of $\mathrm{AFs}$, and the function(s) of each and every $\mathrm{AF}$ as provided by husbands.

Given the lack of systematic study on the use of AFs among Jordanian spouses living in rural areas, this study aims ipso facto at enhancing our understanding of the social meaning interpretation of AFs used by husbands in rural areas, through examining AFs as verbal communication resources. Written AFs do not fall within the scope of this study. Against the terrain of previous studies, this study seeks to answer the following focus questions:

a) What are the conventional AFs used by Jordanian husbands when addressing their wives?

b) What is the impact of age, length of marriage period and educational background on the choice of AFs?

c) What are the functions or social meanings of the used AFs?

d) Does the speech situation as well as the speech act affect the choice of AFs made by husbands?

\section{Jordanian society, rural community and addressing women}

A man may use different forms to address a female of various relationships in different contexts. This may include the female first name (e.g. Rabab), title (e.g. Madam), occupational term (e.g. Doctor), kinship term (e.g. zawjati, 'my wife'), polite, endearment or pet name (e.g. Sazizti, 'my dear'), flora terms (e.g. wardah, 'rose'), terms denoting royalty (e.g. Pmeerah, 'princess'), teknonyms (e.g. Pom Sami, 'the Mother of Sami'), epithets (e.g. Ћabibti, 'my love'), coinage from personal names or adjective undergoing some phonological processes so that coinages become hypocoristic names through such processes as duplication (e.g. lam-lam for Lama), insertion (e.g. Joudi for Joud), deletion

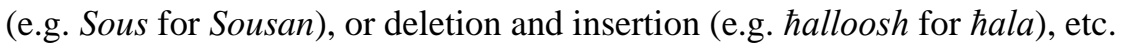

The relationship between spouses is likely to affect linguistic forms, including AFs used. This has been stressed by Brown and Ford's (1961) study of American English, which highlights that status and intimacy between interlocutors are the two main determining factors for choosing AFs. The forms used may indicate setting the tone for the interpersonal exchanges, and setting the relative power and distance between the speaker and the addressee (Wood \& Kroger, 1991:145). This calls for understanding the socio-cultural background of the Jordanian community under study as argued by Saville-Troike (1997: 126):

In understanding [...] communication in a particular locale, the first task is to 


\section{A Sociolinguistic Study of Husband-to-Wife Address Forms and Functions in Rural Jordanian Community}

define at least tentatively the speech community to be studied, attempt to gain some understanding of its social organization and other salient aspects of the culture, and formulate possible hypotheses concerning the diverse ways the socio-cultural phenomena might relate to patterns of communication.

In general, Jordanian society has an array of forms for addressing women. Using AFs usually follows socially understood and appreciated rules. Differently put, if a man uses a particular form, he knows that he is "assign[ing the addressee] a particular role [or position]" (Goyvaerts, 1972:4), as being a superior, inferior, a relative, intimate, and so forth. As insiders of the Jordanian society, one may expect madani men (living in urban areas or most likely very westernized modern parts of western Amman) to use hypocoristic names or epithets for female friends, classmates and colleagues, and between spouses and lovers. Conversely, when it comes to fallahi and qarawi ('rural areas') men, these forms are expected to be very private and used only between lovers or husband and wife. Men in Bedouin communities are likely to have their own patterns of addressing women. However, globalization, westernization and technological revolution have impacted the all walks of life and relations, hence introducing a change in how people approach and address one another.

Shedding light on the rural community, according to the World Bank's 2015-collection of development indicators (tradingeconomics.com), rural population in Jordan constitute $16.32 \%$ of Jordanians living over a large geographical area that amounts to 86229 square kilometers. Families in rural areas are very traditional and care very much about maintaining the traditional role of man and woman inside the family as well as in front of others. The husband and the wife in the Jordanian society have duties and responsibilities that sometimes are deemed equal, inter-dependable or independent. According to the spouses' roles, their relationship could be symmetrical or asymmetrical and determine the level of intimacy and distance, and thus the linguistic AFs. This is underlined by (Philipsen, 1975) who views each community as having its own cultural values about speaking, and such values are linked to interactants' judgment of how appropriate the way of speaking is in a situation. The same view is the drive behind asking the participants in this study to inform us how they judge the way they address their wives.

Social life in Jordanian rural community always centers on the family and behaviours of every family individual towards the family members. In Jordanian rural areas most people work in the public sector, mostly in agriculture, teaching, the military and the security agencies. Women in rural Jordan occupy an inter-tribal and inter-familial importance. They are also expected to bear the responsibility of most household chores; yet, it is men who are expected to be looked up all the time. Wives, on the other hand, are generally looked at as subordinate to their husbands. It is still the normative role and influence of the husband to 
support the family, especially the wife, morally and financially.

Nevertheless, in general, rural Jordanians admit the roles and duties of both wife and husband as stated in the teachings of Prophet Mohammad: "All of you are guardians and are responsible for your wards. The ruler is a guardian of his wards; the man is a guardian of his family; the woman is a guardian and is responsible for her husband's house and his offspring; and so all of you are guardians and are responsible for your wards". Men and women, accordingly, have their responsibilities to assume. Meanwhile, men are aware of the Quranic verses that call men to treat women with care and kindness, as in "And of His [Allah's] signs is that He created for you from yourselves mates [spouses] that you may find tranquility in them; and He placed between your affection and mercy. Indeed, in that are signs for people who give thought." (30:20) (1) Therefore, faithfulness to intimacy, love and mercy between spouses are encouraged to be there and to remain as a significant force between spouses.

However, some social tribal traditions also affect the affinal relationship and encourage typical and established practices. The same relationship may be expressed and reinforced through different socio-cultural practices, including linguistic forms and behaviours such as AFs. In social gatherings, for example, women are expected to sit in a different hall or room to guarantee their privacy, unless the gathered men are close relatives of women with whom they may sit. In the event the man wants to speak to, call or request his wife in the presence of non-close attendees, certain AFs are conventionally used between spouses, mainly teknonyms. Therefore, using the proper AFs requires considering several factors, including formality of the setting, interlocutors' roles, social status, degree of intimacy, interlocutors' emotional state, the presence of out-family persons, and so forth. Therefore, different forms might be used in the presence of close relatives or when spouses are alone. This spouse (subordinate and responsible) relationship is influenced by Arabian and Islamic culture which dictates the social norms of society against which the appropriateness of AFs, as a social behavior, should be measured. Nonetheless, how characteristic, patterned or fluid, functional, and situation and social variable-governed AFs in rural community are is worth investigation.

\section{Theoretical background and literature review}

In this study, it is hypothesized that the socio-cultural context in which AFs are used as well as a number of social factors such as sex, age, attendees/participants, educational level of spouses and the social distance between the participants who are involved in

\footnotetext{
(1) Capitalization in the quoted text is reflecting the source (i.e. Quranic) style of capitalization of all pronouns referring to allah/god as a mark of glorification.
} 


\section{A Sociolinguistic Study of Husband-to-Wife Address Forms and Functions in Rural Jordanian Community}

interactional events and at the entry point to a speech/communicative act have a fundamental impact on AFs used by husbands and for various functions. It is also hypothesized that similar AFs might be used in different events and settings by husbands coming from rural Jordanian areas to address their wives, but to signal different social meanings that are situation dependent. The present study, consequently, hypothesizes the validity of the argument made by Watts (2005) that AFs might not express politeness, and, therefore, adopts the position that the AFs' functions are varied. This study also comes out to verify Hymes' (1972) note on the value of examining the social meaning of particular communicative choices to those who make them. Investigating the linguistic forms that husbands use to address their wives may, therefore, inform us about how the affinal-social relationship look like, especially when used to enter to a communicative event or initiate a speech act.

Drawn on Brown and Gilman's (1960) two-dimensional model, Hymes' (1962, 1964, 1972) ethnography of communication (cultural communication theory), this study is intended to throw light on whether or not AFs as communicative resources in rural Jordanian spouse interaction reflect any distinctiveness of Jordanian culture, and thus show a practical value of forms in managing human relationships in rural settings. Following the classic studies of Brown and Gilman's (1960) study on pronouns of power and solidarity and Brown and Ford's (1961) study on address in American English, research on AFs has been conducted (e.g. Parkinson, 1985; Winchatz, 2001; Farghal \& Shakir, 1994; Oyetade, 1995). Brown and Gilman (1960) have presented a two-dimensional model which presents two social relations encoded in language: power and solidarity (as in T/V deictic function). Brown and Gilman define the power semantic as asymmetrical. When an imbalance of power is symbolized in speech, it is usually done by those with more power using the informal pronoun and receiving the formal pronoun from those with less power (Winchatz, 2001:339). The solidarity semantic represents more balance between individuals and is symmetrical. Power reflects relative superior status, social distance and deference; and solidarity reflects closeness, common experiences and shared intimacies (Brown \& Gilman, 1960).

Concerning AFs by rural husbands, it might be only deference or politeness that is triggered in an AF but not all the relations of power. Therefore, in the present study the intended function or social meaning relationship will be presented as a major social meaning. Every language has some way of signaling relationships of power and solidarity (Hudson, 2001:123), and different societies may present what is beyond power and solidarity or what cannot be understood as part of power or solidarity. This could be what has led Friedrich (1972) in his study of the Russian pronouns-use to propose a third dimension, intimacy, to allow social meaning like 'closeness, liking, isolation, etc.' to be 
more easily accounted for, as Friedrich sees that such meanings are not necessarily aspects of solidarity relationships. What is more, there have come theorists to challenge Brown and Gilman's two-dimensional model. Among these theorists is Fitch (1991) who adopted a cultural approach, which discovers the meanings of AFs shared by a particular group of people, so as to study the situated meanings of AFs in Columbia. Fitch argues that AFs serve a referential 'pointing' function; that is, invoking identities and norms like showing respect and establishing a definition for the relationship between the interactants. Along the same line of Fitch, the present study explores the situated use of AFs by a particular group of Jordanian people in an attempt to find out the potential 'pointing' functions that are also believed to be underlying lead to the choice of AFs and their meanings.

Hymes (1972:2) urged researchers to examine the 'means of speech [...] and their meanings to those who use them'. By adopting this approach, researchers focus on the variety of meanings brought by speakers to their interactions (Winchatz, 2001). According to Hymes' (1964), 'ethnography of communication' entails the analysis of communication within the wider context of the social and cultural practices of the members of a particular speech community: it investigates the use of language in contexts of situations so as to discern patterns proper to speech activity, and it takes as context a community, investigating its communicative habits as a whole. This means that linguistic form and function in a community's communication is integrated with considering the socio-cultural context of its use and functions of the conveyed meanings. Having said that, 'ethnography of communication' for the purpose of the present study is used as a means to study how members of a specific speech community, like a fallahi/qarawi/rural speech community, interact with certain speaking norms and codes. In this sense, the present study is a response to Hymes' call, by analysis of patterns of Jordanian husbands' situated use of AFs in spouse interactions, and the meanings of AFs to the husbands.

Literature shows a number of social meanings and functions that could be conveyed by means of AFs. AFs have the power to indicate how the addresser relates to the addressee socially and emotively. That is what has led Chaika (1982:46) to conclude that AFs are 'social selectors' and powerful controllers of interaction. The very finding was stressed by Ruhlemann (2007:085) who has noted that AF-choices indicate the social relationship that the speaker perceives to exist between him or her and the listener or listeners. As a result, studying AFs as entrance points into communicative acts may decode more information, given that every communicative act encodes both a referential meaning and a social meaning (Winchatz, 2001:338). The social meaning of a communicative act expresses and is made up of the following: who the speaker believes he is, who he believes the addressee is, what he thinks their relationship is, and what he thinks he is doing by saying what he is saying (Parkinson, 1985:5). 


\section{A Sociolinguistic Study of Husband-to-Wife Address Forms and Functions in Rural Jordanian Community}

Afful (2006) states that linguistic resources used in AFs may reflect a culture that could be described as warm or cautious, etc. Such reflection and wealth of information that could be conveyed by AFs have been emphasized by Ruhlemann (2007) who has noted that AFs can mark entering an interactional event and the speaker's interactional position or stance. This information implies that a successful interaction requires appropriate mode of address, and that AFs have the potential of signaling social and cultural meanings as well as fulfilling certain functions.

The functions may include, among others, the usage of AFs to attract the addressee's attention (Keshavarz, 2001) and employing an AF to appeal directly to the addressee (Taavitsainen \& Jucker, 2003). AFs may also reflect social information about identity, gender, age, status and complex relationships in a speech community (Yang, 2010). In other words, AFs can be used to remind interactants with their own position and status. It can be said that AFs are essential for successful communication and in any interpersonal relationships, and are considered as an indicator of how healthy a relationship is.

However, being society, culture and situation-related, and sometimes unpredictable in terms of their use by the speaker or their perception by the addressee, this makes applying the appropriate AFs and interpreting the intended social meaning not an easy task. Agha (2007:278) argues that AFs include two indexical layers: participant deixis which denotes the speaker or the addressee, and stereotypic social indexicals which are indexicals of the speaker's attributes and the relationship between interlocutors. Based on what has been mentioned, understanding how AFs are used and how they interpret from the perspective of the speaker is worthwhile and a powerful entry point to better understand the dimensions of social relationships in rural Jordanian areas.

Along the line of Hudson's (2001:123) note on that every language has some ways of signaling relationships of power and solidarity, and Brown and Yule (1989:54) contend that "different [forms] of address will be used" in "different social contexts". It is believed that characteristic relationships, social meanings and functions may be signaled in Arabic speaking Jordanian rural speech community, a thing will be verified in this study. Meanings, functions and attitudes might be conveyed in different patterns of AFs that have the norm of keeping the kind of relationship that one wants to maintain (Thome-Williams, 2004:85). In a sociolinguistic study of the modern Persian AFs used in Iran, Aliakbari and Toni (2008) have found various types of AFs being used in various contexts. The identified forms include occupation titles, personal pronouns, kinship terms, personal names, honorifics, religious expressions, terms of intimacy, and descriptive phrases.

Differences in the used patterns also entail the existence of various context, society and culture dependent rules which govern the selection of AF patterns. People in English and American societies, for example, can address one another using four main patterns: name, 
title, both name and title, or no naming at all (Yang, 2010:743). Which social meaning is more important may vary cross-culturally. Okamura (2002:71) states that in English and the majority of European languages, solidarity takes precedence over power in choosing AFs between dyads. Okamura (2002:72) points out that in a modern free society, familiarity takes priority over power, and "familiarity seems to be related to having more variations in address terms". This makes exploring precedence of various social meanings over one another in the Jordanian community worthwhile.

In conformity with the culture of the speech community, communicators may prefer to use certain AFs in order to attain a successful communication. This very influence of culture on the use of linguistic forms has been stressed by Wierzbicka (2010) who has expressed that English, for example, is not culturally neutral; it is rather steeped in the Anglo culture. Stressing the influence of culture on the used AFs, Afzali (2011) has found that Islamic culture characteristics of the Iranian society mainly affect the way spouses use address terms toward each other. Afzali underlines the use of the title 'haj' as a respect title. This is why the present study intends to show any systematicity when it comes to AFs and function thereof in Jordanian rural areas' husbands' use.

So, various factors may influence AFs' employment, including inter alia culture, geography, class, race, gender, age, religion, and the like (Labov, 1972). Social variables as well have been of a paramount significance in dictating that AFs should not be chosen randomly. Rather, they are governed by speaker-related factors, addressee-related factors, speaker-addressee relationship, and where and when (Parkinson, 1985). Oyetade's (1995) descriptive analysis of AFs, used in a language spoken in the western part of Nigeria, has ended to that the choices made by interlocutors are influenced by social relationship between interlocutors and some social governing factors such as age, social status and kinship. In his description of the socio-cultural setting-related AFs in Hindi, Mehrotra (1985) has noticed that variation in the used AFs reflects the interlocutor's social background and they define identity and status of the speaker and addressee. These studies emphasize the need to consider the various social factors when it comes to studying AFs in any context- a thing sought after in the present study.

For example, to demonstrate the influence of various factors, a few studies need be referred to. Sociolinguists' studies of gender show that a "woman's register" maintains women in an inferior role in social life and show gender differences in communication styles (Lakoff, 1975). Concerning geography, difference in regions of the same country has been found to affect the use of AFs and their interpretations (Yang, 2010). Yang's (2010) finding implies that people coming from rural areas may use AFs differently from those coming from urban areas, a thing that has encouraged me (the researcher) to focus on a certain area of Jordan. Moreover, the same AFs may be used for different social functions 


\section{A Sociolinguistic Study of Husband-to-Wife Address Forms and Functions in Rural Jordanian Community}

in the same (or different) region. Nevertheless, although the use of the same AFs serves communication, it could be looked at as a "regional marker" (Yang, 2010:744). According to Yang, using first names, for example, in North America is usually used to refer to someone contemptuously, while in South America is a mark of intimacy. Yet, in South America, the absence of certain AFs "in situations where they are expected [to be used] is considered rude and disrespectful". Such scholarly findings have been a drive for studying AFs in the Jordanian rural areas which may act as regional markers.

The setting has been found in literature as a potential factor of influence. Keshavarz (2001:6) stresses that setting, whether formal or informal, is essential because linguistic as well as social behavior needs be suitable for the interlocutors' social characteristics and the situation wherein AFs are used. This highlights the significance of the setting and formality of context as a determining factor for what AFs should (not) be used. The same reason has made it necessary to investigate the use of AFs in the present study in various settings and situational contexts.

When it comes to the age factor, AFs are argued being governed by the age of interlocutors (Fasold, 1990). A variety of AFs might be used by interlocutors as a mark of respect to the age factor, even if limited. Based on her study about the American society, Ervin-Tripp (1972:220) points out that limited terms are usually used between interlocutors of the same age; however, age difference may continue to have an impact on choosing address terms in different societies or when that difference becomes of the size of a generation. Wang (2003) states that age in the Chinese society, for example, is essential in determining which address term to use: the Chinese see it the older the addressee the more politeness is required from the younger speaker to show in address terms in Chinese culture. This age impact may (not) be present among spouses, and thus has been brought into investigation in this study.

Within the scope of studying AFs between spouses, and the potential variations among social classes, Afzali (2011) has investigated the different address terms applied between husbands and wives in Iran, and any indications of these terms to power and solidarity between spouses. Using a questionnaire, Afzali has collected data from 97 participants of different social classes. Afzali has found an effect of religious characteristics of Iran's society on the way spouses use address terms towards each other, as in using the title 'haj' as a respect title. Men of lower class tend to use their wives' first name, and some others use titles like khanom ('madam'), to address their wives, but rarely do they use the word zan ('woman'), to address wives. Men of middle class tend to address their wives with affectionate terms like khanomi ('my lady'), and endearment terms like aziza ('my dear'). The educational level of spouses has also been found of effect on the used AFs and their social meanings. Afzali has found that the higher the educational level of women, the more 
solidarity exists between spouses.

Succinctly stressed, drawn on previous literature's approach to AFs and their social meanings and influencing factors, this study is conducted to explore the AFs and social meanings signaled by husbands when addressing their wives in rural Jordanian areas, while considering various socio-cultural factors. As attitude related to gender differences, and status of women can be revealed through linguistic behavior (Cameron, 1992), the attitude of community under study towards a particular sex (females) will be demonstrated as reflected in the linguistic forms (AFs) used to address the opposite sex. By studying AFs used by Jordanian men coming from the rural areas, it is expected to define some social markers specific to men's attitudes and relationship with their wives in certain areas of Jordan. Literature has also underlined that AFs are necessary for all, including spouses, to maintain effective and successful relationship and interactions. The reviewed literature has also provided a view over methodology that can be used for data collection and analysis. It serves as a pedestal upon which the rest of this study will be founded.

\section{Methodology}

\subsection{Participants of the study}

A total of 20 randomly chosen Jordanian husbands living in northern rural Jordanian areas (Mustaba and el Kettah of Jerash, and al Kurah and bani Kananah of Irbid) constituted the participants of the study. The choice of those participants was made because they were thought to best represent a large population of Jordanian rural areas, and thus make it feasible to reach more generalizable findings. In addition, my work with people from these areas made it more convenient for us to invite the study participants.

20 husbands living in the northern part of Jordan were invited directly to participate in the study. A purposive method of sampling was used. It involved inviting participants who met the criteria set by the researcher: married and belonging to different age groups, educational levels, and varied length of period of marriage. The participants were divided into two age groups (24-34 year old participants group, and 35-45 year old participants group), two husbands' educational level (secondary school level and lower, and bachelor's level and higher), and three groups of length of period of marriage (1-5 years long group, 6-10 years long group, and >=10 years long group). This helped set the variables against which the identified AFs will be weighed.

\subsection{Data collection instrument and procedures}

To elicit the AFs and their intended functions and meanings as used by Jordanian husbands as an entry point to a speech act/communicative event, discourse-completion task (DCT) was used to prompt the use of AFs as well as the speakers' interpretations of communication. The methodological paradigm of this research is based on the assumption 


\section{A Sociolinguistic Study of Husband-to-Wife Address Forms and Functions in Rural Jordanian Community}

that observable differences in the choice and variation of AFs and social meanings, as used by Jordanian husbands upon addressing their wives, may originate from the social role and kind of stereotypical relationship between the husband and the wife in rural areas, in relation to other sociological factors such as age, spouses' educational level, length of marriage period.

DCT is believed to be exploratory in terms of prompting factors that are of paramount importance to this study. DCT technique can capture the required data to answer the study questions. DCT (see Appendix 1) consisted of three parts. In part one, participants were requested to provide personal information such as age, level of education, place of residence, the length they have been married, whether the wife is older or younger than the husband, whether the wife's educational level is similar, lower or higher than that of the husband. This part is believed to help set the social variables that may influence the choice of AFs. In part two, husbands are asked two questions. The first asks about the form that participant husbands usually use to address their wives when at home, while the second asks about the form that is usually used when outside home and in the presence of people other than their children. This part is intended to find out the conventional AFs that are generally used irrespective of the situation. In part three, 12 real life situations were introduced, and to which participants were to respond. The situations were designed to focus on how to address a wife when entering into an interaction event/communicative speech act of: complaining, greeting, inviting and requesting, when spouses are alone, in the presence of the wife's parents or siblings, and in the absence of presence of the husband's parents or siblings. To ensure the reliability of the research instrument, it was given to four married (rural) friends who assured the familiarity and reoccurrence of such situations in their family lives.

Concerning the procedure, I approached the participants directly, making use of my friends' network. I introduced the instrument and its purpose to the participants to gain their utmost cooperation in a family related topic. The participants were reassured that the elicited data would be used for the research purpose and would not be disclosed. The participants were asked not to write their names on DCT forms. All these procedures helped them feel comfortable in responding to what is perceived personal and private. Participants were directed to write down all words, expressions and terms they usually use to address their wives in the introduced situations, and why they select that particular form.

\subsection{Data categorization}

To give a general view of the conventional AFs used by husbands at home and when outdoor irrespective of the situation, responses to part 2 of DCT were counted and analyzed. Nevertheless, to examine the assumption upon which the methodological paradigm of this research is based, the number of AFs was collected from participants' response to part 3 of 
DCT (the 12 situations) and was then analyzed for the components. Employing the participants' responses to the DCT tool, an AF set was formulated. For instance, an AF could be comprised of one word (e.g. Maryam) or two word components (e.g. Pomm Sali, 'the mother of Ali'). The presence of each AF was calculated for frequency of use for the participants, and then I worked out the percentage score for each form. By way of comparison, the percentage scores for the different AFs were presented in the form of tables: to present the identified AFs, components in one table, and to show the set of AFs distributed to the social factor of participants' age, spouses' educational level and length of marriage period.

The responses to the 'why part' of DCT situations concerning the use of each and every $\mathrm{AF}$ have helped formulate a set of social meanings and functions for each AF. This led to introducing a comprehensive set of intended functions or social meanings of all AFs and underlying attitudes thereof. Therefore, the influence of each communicative act type/ interactional event on the intended functions/social meanings of each AF was traced. This helped conduct a comparison on how the intended meanings of the same AF vary across the various communication events. The result was having AFs and respective functions in invitation, requests, greetings and complaints, depending on the subject's response.

\section{Results and discussion}

Results of analysis regarding the identified AFs and pertinent effecting factors, and the social meanings along with selected examples and discussion in light of previous studies will be detailed under three main headings that are based on the study questions: first, the most persistent AFs; second, the impact of social factors on the choice of AFs; third, the choice and functions of AFs in relation to the situation/setting and communicative event.

\subsection{The most persistent AFs}

Based on the analysis of the gathered data from part 2 of DCT, two main AFs were conventionally used by husbands when spouses are at home and when they are outdoor or in another's home: teknonyms and forenames. Analysis showed that Taknonymy seems to be the most favored when spouses are outdoor or accompanied by people other than their children (when not alone) with a percentage of $66.7 \%$. Whereas it was selected by $16.6 \%$ of the husbands when spouses were inside home, and when there were no people other than their children. Forename was the second choice, with a percentage of $33.3 \%$ of frequency of use when spouses are outside their house or in the presence of people other than their children. However, it was the preferred form when spouses are alone in their house or in the presence of their children, with a percentage of $83.4 \%$.

However, these frequencies appeared to change when it came to the analysis of use of AFs in specific situations and before entrance to certain communicative acts. Analysis of 


\section{A Sociolinguistic Study of Husband-to-Wife Address Forms and Functions in Rural Jordanian Community}

used AFs in certain situations has supplied a larger set of AFs with various frequencies. Table 1 below presents the identified AFs, their components, examples, and how frequently each form was almost used.

Table 1 . The identified address forms

\begin{tabular}{|c|c|c|c|c|}
\hline $\begin{array}{l}\text { Address } \\
\text { Forms }\end{array}$ & Components & $\begin{array}{l}\text { Equivalent/meaning } \\
\text { in English }\end{array}$ & Examples & $\%$ \\
\hline Zero form & $\begin{array}{l}\text { no use of any linguistic form made, } \\
\text { with occasional extra-linguistic } \\
\text { features (e.g. frowning, smiling, etc.) }\end{array}$ & zero form & - & 41.5 \\
\hline Teknonyms & Pom + name of eldest son/ daughter & $\begin{array}{l}\text { omm ('the mother } \\
\text { of') }+ \text { name of eldest } \\
\text { son/ daughter }\end{array}$ & $\begin{array}{l}\text { Pom Samir ('the } \\
\text { mother of Samir') }\end{array}$ & 27.7 \\
\hline Epithets & $\begin{array}{l}\text { descriptive loving word }+ \text { the first } \\
\text { person possessive suffix }-i \text { ('my') }\end{array}$ & $\begin{array}{l}\text { my }+ \text { endearment/ } \\
\text { loving word }\end{array}$ & $\begin{array}{l}\text { hayati ('my life'); } \\
\text { habibti ('my love') }\end{array}$ & 18.5 \\
\hline Forenames & the wife's first personal name & forename/ first name & Wala?; Sara; Rabab & 10.8 \\
\hline $\begin{array}{l}\text { Endearment } \\
\text { terms }\end{array}$ & $\begin{array}{l}\text { kind word }+ \text { the first person possessive } \\
\text { suffix }-i\end{array}$ & endearment terms & $\begin{array}{l}\text { Sazizti, yalyah ('my } \\
\text { darling/ sweetheart') }\end{array}$ & 1.5 \\
\hline
\end{tabular}

From the data, it became evident that husbands conventionally used five persistent categories of AFs that constituted the linguistic repertoire of addressing wives in various situations: zero form, teknonymy, epithets, forename and endearment terms. Analysis showed AFs by husbands. Zero form was the most preferred way to enter into a communicative event, with a percentage of $41.5 \%$. Zero form refers to the situations where no linguistic form was used by the husband to address his wife. Nevertheless, although that lack of use was most of the time neutral and appearing in different situations, it seemed to have been accompanied by extra-linguistic features (e.g. frowning) when in complaining situation for example. A potential reason of this high frequency of appearance of this category of AFs could be related to its use in all situations under study, yet for different functions. Mention of the potential functions of forms will be made in a later sub-section.

Teknonymy refers to the situations of referring to the wife as a parent. Teknonyms constituted the second most frequent AF in terms of frequency of use (27.7\%). Analysis showed that a husband used it to refer to his wife by the name of her eldest son (or daughter in the event of having no sons), for example ?om Sali ('the mother of Ali'). Even in the event of having a son that is younger than the daughter, a wife is addressed by the name of that son. When a participant husband had no sons or daughters, he was found used to referring to his 
wife by a name of a future son. This practice of use of Teknonymy is cultural and can be found in all the Arab world.

Epithets were the third in frequency of use (18.5\%). Epithets refer to the situation where a husband used any adjective, descriptive word or a phrase that expressed a quality, and how precious the wife was to him. In a phrase such as ћayati ('my life'), a husband replaces his wife's name and uses a word hayat ('life') to indicate that his wife is as precious to him as his life. The use of the first possessive pronoun $i$ along the descriptive word adds a shade of meaning of closeness and intimacy. The same effect is in the use of $\hbar a b i b t i$ ('my love'). This $\mathrm{AF}$ was an occasion specific form which did not appear but in certain very private context, as will be elaborated later.

Forename refers to the given name, i.e. the name that was given for someone's wife at birth, such as Wala?. This form was the second least used option (10.8\%), while endearment terms category made up the least used $\mathrm{AF}(1.5 \%)$. An endearment term refers to a word (e.g. falyah, 'sweetheart') or a phrase (e.g. Sazizti, 'my darling') to address or describe the wife by means of affection or liking that the husband feels towards her. The connotations which such terms may carry proved dependent on the situation and social context, a thing that will be highlighted later. Interestingly, concerning teknonyms presented the only AF with a combination of two separate words (e.g. ?om Sali). Unlike teknonyms, other forms (particularly, epithets, forename and endearment terms) were made up of one word structure which implies closeness and intimacy.

\subsection{The impact of social factors on the choice of AFs}

When taking the various social factors into consideration, it becomes evident that some factors had some impact on the decision and distribution of which AF to use, while other factors had no effect at all. It is worth mentioning that all husbands were older than their wives, which reflects a norm and praised practice by rural Jordanians. The factor of age of wife, therefore, was not traced in this study. Considering the husband's age factor, the husband's educational background/level, the wife's educational background and the length of marriage period, Table 2 below demonstrates the distribution of AFs which appeared to have been used by each group of each social factor. Whenever 'yes' is mentioned across each AF, it means it has been used by the respective group/sub-group. Conversely, 'no' refers to the absence of use of a particular AF by the respective group/sub-group. 


\section{A Sociolinguistic Study of Husband-to-Wife Address Forms and Functions in Rural Jordanian Community}

Table 2. Distribution of AF choice by social factors

\begin{tabular}{|c|c|c|c|}
\hline \multirow{3}{*}{ Address forms } & \multicolumn{2}{|l|}{ Social factors } & Examples \\
\hline & \multicolumn{3}{|c|}{ Age of husband } \\
\hline & 24-34 years & $35-45$ years & \\
\hline Teknonyms & yes & yes & \\
\hline Forename & yes & yes & \\
\hline Zero form & yes & yes & - \\
\hline Epithets & yes & yes & \\
\hline Endearment terms & yes & no & \\
\hline \multicolumn{4}{|c|}{ Husband's educational background } \\
\hline Address forms & with high school certificate/Tawjihi & with a degree & - \\
\hline Teknonyms & yes & yes & \\
\hline Forename & yes & yes & \\
\hline Zero form & yes & yes & - \\
\hline Epithets & no & yes & \\
\hline Endearment terms & no & yes & \\
\hline \multicolumn{4}{|c|}{ Wife's educational background } \\
\hline Address forms & lower than the husband's & similar to the husband's & higher than the husband's \\
\hline Teknonyms & yes & yes & yes \\
\hline Forename & yes & yes & yes \\
\hline Zero form & yes & yes & yes \\
\hline Epithets & no & yes & yes \\
\hline Endearment terms & no & no & yes \\
\hline \multicolumn{4}{|c|}{ Length of marriage period } \\
\hline Address forms & $1-5$ years & $6-10$ years & $>=10$ \\
\hline Teknonyms & no & yes & yes \\
\hline Forename & yes & yes & no \\
\hline Zero form & yes & yes & yes \\
\hline Epithets & yes & yes & no \\
\hline Endearment terms & yes & no & no \\
\hline
\end{tabular}

Conforming to previous literature (e.g. Afful, 2006; Afzali, 2011, etc.), AFs used by husbands were found reflecting information about gender and how men in certain 
geography address women, and about the influence of age and educational background on the use distribution of AF's use. Taking into account the distribution of use of AFs by each social factor, Table 2 reveals that the younger group (24-34 years old) tended to use all identified conventional categories of AFs. Interestingly, older husbands showed no use of endearment terms. Keeping endearment terms aside, husbands of different age groups made use of almost the same AFs. Besides, no significant impact of the husband's age on the choice was identified.

Shedding light on the impact of husband's educational background, those with high school certificate/Tawjihi or lower showed the employment of fewer forms than those used by the other group. They demonstrated the use of teknonyms, forename and zero form, while they did not make any use of epithets and endearment terms. Unlike husbands with Tawjihi, those who had a bachelor and higher degrees showed the use of all categories, hence demonstrating more varieties and tendency to use epithets and endearment terms. It could be said that the higher the academic level of speaking husbands, the more linguistic options they proved show ability to employ. This could be explained on the ground that the more educated people are quite aware of their various roles as guardian of their families' values and as caring for the other half's emotions. Less educated husbands, by contrast, tended to ignore the choice of epithets and endearment terms, and thus reflected no observance for intimate interpersonal relationship.

Throwing light on the variable of wife's educational background's effect on the AF used by their husbands, Table 2 presents a tendency among husbands: the higher the educational level of the wife, the more varied forms husbands use to address their wives. Husbands showed the use of all conventional AFs when addressing wives who held higher degrees than husbands'. The same AFs were used to address wives with similar educational level of their husbands, except for endearment terms. In cases where wives had lower educational level than husbands, husbands used more limited choices. They tended to use only teknonyms, forenames and zero form. No use of epithets or endearment terms appeared. It might be concluded in this place that the higher the educational level of the wife is, the more varied AFs husbands are likely to employ in different situations. This could be ascribed to that the more educated the wife is, the more merits she deserves to be addressed by the appropriate form in different situations.

Paying attention to the factor of length of marriage period on the choice of AFs, husbands with less marriage period seems to have tended to use more choices. That is, spouses of the first group (1-5 year-long marriage period) showed disposition to use all AFs except for teknonyms. This might be due to the fact being newly married, and hence not 


\section{A Sociolinguistic Study of Husband-to-Wife Address Forms and Functions in Rural Jordanian Community}

used to addressing each other as parents. At the same time, this group was significant in tendency to use more epithets and endearment terms which were absent among the husbands coming from the third group ( $\geq 10$ years long of marriage). Like the first group's husbands, the second group's (6-10 year-long marriage period) used epithets, but dissimilarly made use of teknonyms and no use of endearment terms. A conclusion that might be established in this regard is that the more the years spent in marriage, the fewer the used AFs become and the less likely that epithets and endearment terms are used, i.e. the more distancing and less affectionate function is signaled. Besides, the younger the relationship between spouses, the more affectionate and romantic it seems; this could be founded on the ground that more epithets and endearment terms are used by the youngest group, and hence indicating more interpersonally emotional and caring relationship.

\subsection{Functions versus choice of AFs in relation to the setting and communicative} act

The 'why' element-analysis of part three of the data collection instrument has informed us about various reasons behind selecting each AF in each situation. The identified reasons were in form of functions which were desired to be achieved and social meanings, effects or attitudes that were intended to be demonstrated. Table 3 presents a set of the overall identified AFs' functions, based on the participants-husbands' interpretations.

Table 3 presents five major social meanings and functions that AFs may convey when used by husbands, and thus mirrors men's attitude towards women in the rural Jordanian areas. These social meanings are: politeness, power, solidarity, status and intimacy. Analysis showed that husbands may refer to different AFs for different purposes, and the same AF may carry different social meanings in different contexts and when entering into different speech acts and events. Teknonyms were used to signal politeness and status. Forenames were used to maintain status or express intimacy. Zero form had the more varied social meanings, namely, signaling power, politeness and intimacy. Epithets conveyed the meaning of intimacy and solidarity as well as endearment terms were triggering the meaning of intimacy. Drawing on Yang's (2010:744) "regional marker" notion, the identified overriding functional import of these specific AFs have the power of introducing such form-function relationship as community specific-social identifiers and markers. 
Awni Shati M. Etaywe

Table 3. Functions of address forms

\begin{tabular}{|c|c|c|}
\hline Address Forms & Husbands' interpretation & Functions/ social meaning \\
\hline Teknonyms & $\begin{array}{l}\text { - a sign of mutual respect social protocol } \\
\text { - a traditional way for addressing } \\
\text { - to save attendee's from jealousy or shyness } \\
\text { - to reflect more respect when not alone } \\
\text { - to maintain privacy of any familial-emotional } \\
\text { relationship } \\
\text { - to remind the wife with shared responsibility, while } \\
\text { saving the husband's face in the case of potential } \\
\text { decline of request }\end{array}$ & $\begin{array}{l}\text { - politeness } \\
\text { - politeness } \\
\text { - politeness (driven by caution } \\
\text { for others) } \\
\text { - politeness } \\
\text { - politeness (driven by caution } \\
\text { for own relationship) } \\
\text { - solidarity plus (caution for) } \\
\text { status }\end{array}$ \\
\hline Forename & $\begin{array}{l}\text { - to keep marginal interpersonal-distance after a } \\
\text { potential decline of request } \\
\text { - to not let the wife think that husband is weak or } \\
\text { inferior to her } \\
\text { - familiarity demands no other term }\end{array}$ & $\begin{array}{l}\text { - (maintain) status } \\
\text { - (maintain) status } \\
\text { - intimacy }\end{array}$ \\
\hline $\begin{array}{l}\text { Zero form } \\
\text { (nonuse of } \\
\text { linguistic terms) }\end{array}$ & $\begin{array}{l}\text { - implicit way of punishment and reflecting anger } \\
\text { about unfavorable act } \\
\text { - indirect way of conveying dissatisfaction with wife's } \\
\text { behavior } \\
\text { - a way to intensify the call for remedial action and } \\
\text { regret } \\
\text { - to save other attendees from a situation of jealousy or } \\
\text { shyness } \\
\text { - (in invitations) invitation per se compensates nonuse } \\
\text { of linguistic term(s) }\end{array}$ & $\begin{array}{l}\text { - power } \\
\text { - power } \\
\text { - power } \\
\text { - politeness } \\
\text { - implicit intimacy }\end{array}$ \\
\hline Epithets & $\begin{array}{l}\text {-stressing closeness and love relationship } \\
\text { - to sound tactful and suit occasion specifics } \\
\text { - stressing common bond } \\
\text { - stressing the inclusive family-relationship and } \\
\text { interpersonal relationship that require cooperation and } \\
\text { sharing }\end{array}$ & $\begin{array}{l}\text { - intimacy } \\
\text { - intimacy } \\
\text { - solidarity } \\
\text { - solidarity }\end{array}$ \\
\hline Endearment terms & - to sound tactful and suit occasion specifics & - intimacy \\
\hline
\end{tabular}

Just as Hudson (2001) found that names are available not only for identifying people but also for addressing them, analysis showed far more than identifying and addressing in the rationale behind using names. Forenames identify status and level of intimacy between 


\section{A Sociolinguistic Study of Husband-to-Wife Address Forms and Functions in Rural Jordanian Community}

interactants. The same applies to all identified AFs which proved being available not only for addressing people but also for signaling the social meanings of politeness, power, solidarity, status and intimacy between interactants. The following sub-sections elaborate on the identified functions and draw the results onto relevant studies, whilst highlighting the influence of the change, namely, in event, speech act, and the attendees/participants settings as determinants of choice of AFs.

\subsubsection{Influence of determinants on the choice of AFs}

In the event there were other people such as a spouse's relatives along with spouses, situations called for the use of forms that avoid triggering the connotations of intimacy such as liking and love. Employed forms included 'teknonyms' so as to convey the social meaning of politeness and respect for the wife. Husbands reported that 'teknonyms' could be used as a traditional sign (protocol) of mutual respect to the wife while showing politeness in treatment in the presence of others. It was a safe choice to make in situations of complaining that occurred in the presence of people other than the family members. Besides, the use of teknonymy could be driven either by caution to protect affinal relationship from envy, or by caution to help attendees (guests) avoid having a potential feeling of jealousy or shyness brought about by any use of intimate and loving words (as in epithets).

That being said, it is obvious that the setting, particularly the participants/attendees, had an impact on maneuvering to choose the appropriate AF. In addition, the interactional event as well as the speech act opened by an AF evidently influenced the decision on which AF was more suitable. This influence was clear in the frequency of AF employment when making complaints, greeting, invitation and request. For example, zero form was used more frequently than other forms ( $90 \%$ of occurrences) in the situations of entering into events of complaining. For example:

(1) la hawla wala quwata Pel la belæh! mひ[ Pana golt lek Pekwih?

'There is no power (and patience) but in God! Did I not tell you to iron it?'

In this example, the husband used zero form and expressed his quasi fed-up expression (There is no power (and patience) but in God, which is a religious expression usually used to pray for solving problems). Then he asked a question that functions as blaming his wife for not ironing his clothes. It is the power-signaling. Zero form was found the most expressive of manhood-power in spouse interaction. Despite using the zero form to express implicit intimacy and politeness (as will be elaborated later), power was the most recurrently intended meaning, especially when it came to complaining act. Zero form was used to reflect anger implicitly about unfavorable act, but with extra-linguistic features, namely frowning or shouting. It was an indirect way to convey dissatisfaction with wife's behavior; and it 
intensified the call for a remedial action and regret. Different feelings and emotions might be sent in the event of complaining if a teknonym was used. Consider the following example:

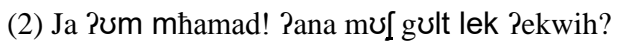

'Omm Mohammad! Did I not tell you to iron it?'

Although this is a situation of complaining, the husband show some respect by using the teknonym while complaining. Pom Mohammad, as a teknonym, highlight the solidarity relationship that should have motivated the wife to do the job of ironing, which is a job traditionally expected to be done by the wife. The forename was also used as in the following example to complain with harshness and ultimate power.

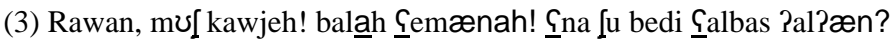

'Rawan, did you not iron? You're kidding me! What should I put on now?'

In this example, the husband was complaining about his wife's forgetting about ironing his clothes. He used forename and then complained. Husbands also used zero form; and asked for alternatives. In the following example, the husband asked for an explanation for not ironing, as in:

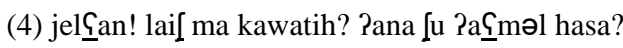

'Damn it! We did you not iron it? What should I do?'

The husband here cursed, as a manner of showing anger, and asked the wife why she did not iron, and then asked her to find a solution. But most husbands mentioned that, in the presence of any sibling or parent of the spouses, they do not shout, curse, or sound furious. They tended to look angry, frown and ask for a solution. All these styles of complaining show power practiced by husbands against wives, and how roles are socially designated for spouses, especially when zero form is used.

However, that use for zero form dropped when it came to greeting, especially when spouses were alone (to about 10\%), for the favor of epithets which were used $46 \%$ of greeting situation occurrences when spouses were alone. In invitations, epithets and teknonyms were the most frequently used (with a percentage of $25 \%$ each). Husbands reflected their habit to avoid inviting the wife when having guests regardless of how close or distant the relationship with gusts is. That norm helps spouses avoid any embarrassment (brought about by inviting only the wife while having guests who could also be invited), and keeps the familial issues, including the habit of outdoor invitations, a family covered issue.

When entering into the speech act of request, husbands indicated a wide variation in the use of AFs and the reasons behind their choice. Husbands showed an inclination to use forename in $25 \%$ of the request-situations to keep marginal distance in the case of expecting 


\section{A Sociolinguistic Study of Husband-to-Wife Address Forms and Functions in Rural Jordanian Community}

declining of request, and hence not making the husband look inferior to his wife, or not letting the wife feel he is weak and in need. Using the forename, therefore, sends a neutral effect with no kindness that might be conveyed in epithets, for example. Any kind or loving words might be understood as a mark of need and weakness. Consider this example:

(5) Pasma! Pana habeb Pedzeded Pasajarah, [u ra?jek?

'Asma! I'd like to change the car. What do you think?'

The husband in this example used forename of his wife Asma (?asma?) when making indirect request for a financial help from his wife. He explained his use of that particular form as 'to not let the wife think that he is weak or inferior to her', so that when the request is likely to be turned down, his status image as a sponsor to the whole family would not be shaken, and it would be his problem to find other alternatives. To maintain that status, the husbands used forenames to keep a marginal interpersonal-distance for any potential decline of request which would be more damaging to his face if he used an epithet or endearment term and then his request gets rejected. Nevertheless, using forenames was present in all situations and with various events and acts because, based on the participants' data, familiarity between spouses demands no other form. In other words, husbands consider over-familiarity and the daily routine breeding less concern about emotional or more politic forms. Back to the request-related AFs, around $25 \%$ of the situations showed the use of teknonyms with requests justified as a 'semi-sure' form used when the wife is more likely believed to not decline the husband's request. It could be described as a 'confidence AF'. For example:

(6) Pom qais! Pahli bjeћku Penek ma rah tsæ

'Mother of Qais! My family are saying that you won't help me improve our status and buy a car. What do you think?'

This example shows that feeling of semi-sureness, which meanwhile stresses the solidarity and bond between spouses as parents, which acts as a motive to move to and take action for the benefit of spouses shared family. In about $50 \%$ of the situations, epithets were used to set the tone and prepare the ground for making a request, indicating to the role of emotions and closeness in managing request, as in the following example:

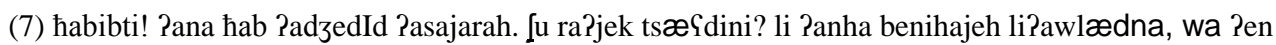
Jalah nethana fiha.

'My love! I'd like to renew my car. What do you think of helping me? Eventually, it is for our kids, and with God will I hope we will have fun with it.' 
ћabibti ('my love') was used to set the tone for an upcoming request for a financial help, which was as well loaded with a solidarity meaning intensified by the reference to the kids that spouses have. Solidarity along with the emotions and intimacy loaded in the use of 'my love' combined are used in the hope of that the wife accepts the request. Epithets were thus used to remind the wife with the inclusive relationship that implies cooperation for the good of the family, hence requiring the wife to share some of her money with the husband. This solidarity signaling function was not the same when the husband used the same epithet for an invitation or greeting. It is worth mentioning here that zero form seemed to be rarely referred to when making requests. Moreover, husbands showed that it is not preferable to request wives when not alone. However, even when there appeared to be a need to request a help in front of the wife's mother, husbands used zero form coupled with a sense of humour in managing the situation that might send indirect messages of need for help, as in the following:

(8) Samti, Reћki la bentlk netsaSed wa neftri sajarah

'My mother in law, tell your daughter to help in buying a car.'

This style of request distanced the husband from the sponsor kind of relationship, and made it as if it was an issue between his wife and her mother who was requested to convince her daughter of the need to help the husband.

Unlike the situations of requests where epithets were used to convey intimacy and solidarity together, epithet was used in invitations and greeting only to signal intimacy, love and closeness. For example:

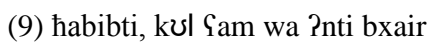

'My love, Happy Eid!'

This shows how the same epithet (ћabibti, 'my love') was used in a different situation (greeting situation) for the cause of expression of greeting on the occasion of Eid. It signals intimacy. However, in situations that involved the spouses' mothers, data showed the use of /kul Sam wa Pnti bxair/ ('Happy Eid') only, i.e. with no use of epithets (i.e. with zero form), with the intention of helping mothers avoid experiencing the feeling of jealousy of intimacy loaded in epithets. Nonetheless, some husbands in invitation events opened their speech with zero form because they found that 'to invite the wife for a dinner out' would compensate any nonuse of other forms, particularly the ones with liking words. For example:

(10) Paljum SamIl lIk mufadze?eh, hed'ri halek

'Today I have a surprise for you. Get dressed to go out!' 


\section{A Sociolinguistic Study of Husband-to-Wife Address Forms and Functions in Rural Jordanian Community}

Invitation per se, according to the husband can be looked at as a tactful behavior that does not require any other tact in forms of addressing wife. Such use of zero forms in invitations are reportedly made most likely when having other people sitting with them. Although it is a zero form, it however conveys intimacy, according to the husband justification. In this sense husbands sound like very economical in kind speech, where they rely on the speech act to compensate for the missing kind AF. Husbands also show concern about attendees at the time of making invitations; this is true because husbands showed examples of using epithets in events of invitation when there were no one of their relatives sitting. For example:

(11) galbi, Paljum Sid zawadzna, wa SamIl lIk mufadze?eh. bedna neћtefel belxared3

'My heart! Today is our wedding anniversary, and I have prepared a surprise for you...we will celebrate it outdoor!'

This example shows how the style of addressing the wife changes when they are unaccompanied. The epithet Plbi ('my heart') was used to enter into an invitation event. The invitation seems justified by the wife being to the husband as his heart. The same epithet paves the introductory road to a special invitation to follow.

It can be said that the functions of used AFs by husbands could be explicit or implicit. They might be own family-sensitive (as in the use of teknonym in the presence of other people instead of epithets to avoid envy against the spouse relationship), or attendeesensitive (as in the pursuit for saving the attendee's face from any potential feeling of shyness or jealousy that might be caused by the use of epithets). So, AFs' functions illustrate an interpersonal and a social dimension at the same time. Some AFs, particularly epithets and endearment terms are used in situations when spouses are alone, while teknonyms, forename and zero form are used in all situations that may involve other people. In other words, AFs in by rural Jordanian husbands have two major functions: distancing function and affectionate function, which both are influenced by place (inside or outside the family house) and attendees (when alone or accompanied). This seems to support Parkinson's (1985:1) point to the effect of place and time on the use of AFs. Findings on determinants are also in support of Keshavarz's (2001:6) emphasis on that setting and formality of context (expressed in this study in terms of spouses (not) being accompanied by other people) is a factor that affects on language use and managing its resources. In other words, linguistic and social behavior need be managed suitably to the situations wherein speaker use AFs socio-intelligently.

\subsubsection{Focus social meanings/functions}

Each function and social meaning of AFs is briefly discussed as follows, drawing on 
examples from the data.

\subsubsection{Signaling politeness}

By politeness here I mean being respectful and considerate. Politeness is a socio-cultural phenomenon which "tak[es] account of the feelings of others", feelings that are "culturally determined", i.e. what might considered polite in one culture or society might not be so in another (Holmes, 1995:285). Jordanian rural husband's politeness revealed their attempt to save face of participants and attendees. In situations of spouses' interaction that may entail some friction, as in a situation of complaining, some tended to use teknonyms that may signal politeness at the same time of expressing anger or dissatisfaction, particularly in the presence of other people, a situation where the wife's face could be lost if not otherwise maintained in a form like teknonym. This kind of politeness in AFs seems to operate in line with what Brown and Levinson (1987:61) stress in that face "can be lost, maintained, or enhanced, and must be constantly attended to". Husbands reported that they tend to use teknonyms to complain in front of spouses' relatives, which is an attempt to attend face wants of both spouses in such situations.

In situations of greetings in the presence of spouses' relatives, husbands tended to avoid epithets when greeting their wives to satisfy the face wants of both the relatives, who might feel jealous (a feeling disrespected by the husband; and the wife who might shy away with receiving loving words in front of others). These kinds of husband's behavior that may involve the choice of zero form instead of epithets, even in a situation of greeting or invitation, can be described as negative politeness which involves negative face wants that should not be unimpeded or lost (Brown \& Levinson, 1987:62). However, when making requests, for example, a husband happened to use teknonyms to address wife in front of his/her siblings and relatives as a traditionally accepted AF or protocol that showed interpersonal respect and satisfied the face wants to be valued, liked, ratified, that is, a 'positive politeness' (using Brown and Levinson's (1987:62) term). In these kinds of culturally determined politeness employment of AFs, AFs were used as a mode of stressing common ground, driven by specific wants of spouses and in proportionate with the local socio-cultural values and goals.

Resorting to appropriate AFs can be conceived as an etiquette applied to avoid being portrayed of bad manners or inconsiderate, which, according to Buss (1999: 804), would make it difficult for a husband to assure the wife or other attendees that he "appreciates the other's intrinsic value". Failing to address the wife appropriately, especially in the presence of relatives, might be perceived as 'an indication of potential ignorance of applicable norms in certain situation-contexts' (Masson, 2001:18). This ignorance can be ascribed to low educational background of the speaker (Owen, 1995), which was indicated in section 5.2 which showed that husbands with higher educational levels were more able than others to 


\section{A Sociolinguistic Study of Husband-to-Wife Address Forms and Functions in Rural Jordanian Community}

make use of more AFs in the different situations. To conclude this social meaning, it can be said that politeness is used by husbands as one of the most conspicuous social meanings that meddle into spouses' linguistic interaction, to show how well-mannered and considerate a husband is; or as Winchatz (2001:358) explained politeness, signaling politeness can be looked at as how much 'admiration for, deference towards and honoring of' the wife and attendees the husband has.

\subsubsection{Signaling power}

By power I mean social capacity and authority to influence the other. Power is another type of social relations that appeared encoded in AFs. Similar to the demonstration of power in the 'T/V deictic function' in Brown and Gilman's (1960) work, power in AFs used by husbands were found reflecting relative superior relationship. This finding is emphasized when considering that every language has some way of signaling relationships of power (Hudson, 2001:123), and some of these ways have come to appear consisting in the use of AFs in rural Jordanian areas. That power-signaling function appeared manifest in the husbands' use of zero form as a linguistic form of punishment, reflecting anger and dissatisfaction with wife's behavior, and a way to intensify the call that requires the wife do a remedial action. An AF such as the zero form has, therefore, perlocutionary effects brought about by the relative power relation between wife and husband.

Zero form, for example, was found a form of imposition involved namely when doing a "face-threatening act" (Brown and Levinson, 1987:15) such as complaining. The power differential between the wife (the addressee) and husband (the speaker) and the relevant imposition might be related to the social norms that ascertain power and leadership to be in the hands of the man, even if he is uneducated or unable to assume that role. Adopting Brown and Gilman's (1960), Oyetade (1995) stated that power refers to "authority or superiority of one person over another". This explanation may stand valid in view of appearance of 'power' as a social meaning triggered by the husbands' report on their use of zero form in situations that include only spouses as well as other attendees, including the children and spouses relatives, hence making complaining with introductory zero form appear like an expected and routine practice by the one with authority and superiority. In other words, the choice of triggering the power function in an AF has been determined by the social characteristics of participants and the setting.

\subsubsection{Signaling solidarity}

Solidarity here refers to a bond in feelings and actions for a common (e.g. family) interest. This meaning can be inferred from Winchatz (2001:358) who mentioned that solidarity is a feeling of unity or commonality between people that can be based on group 
membership; and it can exist when the interest outside of the self is held common to more than one individual. Analysis showed that although I expected husbands to use teknonyms in requests to signal solidarity and remind wives with their children, towards them both parents have responsibilities to bring about better conditions such as buying a car, it proved that teknonyms when used in requests involved a combined function. They were used to signal solidarity in addition to leaving some distance as part of caution for status. Nevertheless, solidarity was the main and the only aim of using epithets when making requests, though intimacy was involved as an auxiliary aim.

To achieve solidarity, epithets were used more frequently than other AFs to stress the one family relationship that required cooperation and sharing belongings, including money. This expression of the inclusive (one family) bond that encourages unity in action such as giving money is stressed by the bond in feelings as expressed, for example, in the interpersonal pronoun (/i/ ('my') as appearing in the end of the phrase habibti ('my love')). Using epithets and interpersonal pronouns expresses a deep bond of belonging with others. Not only when making requests but also when greeting and inviting the solidarity meaning was emphasized. To greet a wife on Eid or wedding anniversary, for example, constituted an occasion of giving emphasis to the solemn inter-personal ties existing between spouses. It was the same kind of tie that led a husband to invite his wife to a dinner outdoor in an attempt to appreciate the affinal relationship.

In other words, signaling solidarity whether by means of epithets or teknonyms, for example, reflects rural husbands' respect for interpersonal relations and the solemn bond by way of settled socio-cultural conventions. In affinity with Brown and Gilman's (1960) T/V deictic function of solidarity, AFs used by husbands in this study demonstrated solidarity that entails closeness, common experience and shared responsibility. Epithets and teknonyms as used by rural husbands displayed, as Hudson (2001:123) put it, a way of signaling relationship of solidarity in Arabic language.

\subsubsection{Signaling status}

Status here means a given social position which entails the speaker's (husband's) rights and responsibilities in some social situations, where, for instance, the husband is expected to sound superior while the addressee (wife) sounds either equal or inferior. Husbands in this study used teknonyms and forenames to signal status. Signaling status in the use of teknonyms (before making requests) came as part of a function sought along with solidarity. By addressing her as a parent, the husband wanted to remind the wife with his status as a father and custodian of the family and her status as a mother who also fell under his care (though she had other responsibilities). This employment of teknonyms might help save the husband's face in the case of potential decline of request that would not change the fact that he is the father and thus the one in higher status, even when he is in need. Similar to the 


\section{A Sociolinguistic Study of Husband-to-Wife Address Forms and Functions in Rural Jordanian Community}

findings of Brown and Ford's (1961) study, this study stresses that status between interlocutors is a determining factor for selecting the forms of address.

The AF which represented the most direct way of demonstrating status was via 'forename'. Although forenames were reported as mostly used when at home and not in front of people other than the family members, it was purposefully used in times of making request, in particular, to achieve one of the following functions: first, to keep marginal interpersonal-distance fearing of a potential decline of a request and; second, to not let the wife think that husband is week or inferior to her. This finding is similar to Goodenough's (1965) point in relation to the status as being determinant of concerning rights and duties.

\subsubsection{Signaling intimacy}

Intimacy in this context means a close or private familiarity. Intimacy, as a social meaning, occurred to be the wanted effect by husbands, namely in the situations of greeting and inviting wives. To convey this particular meaning, husbands appeared to use a wide variety of AFs. They used epithets, forenames, zero form and endearment terms. Only teknonyms seemed to be not used to send the intimacy message.

Epithets, for example, were used to stress closeness and love relationship, and to sound tactful and suit occasion specifics. The latter interpretation of function was the same effect intended by the use of endearment terms. Intimacy was more apparent in epithet use than in any use of other AFs. Intimacy was also the only effect wanted behind the use of endearment terms, probably because of the inner structure of these two AFs which involved descriptive loving word(s) or kind word(s) in company with the first person possessive suffix -i ('my'). Forenames, were used at home by reason of the familiarity that existed between spouses; such familiarity according to the husbands might be a major reason to use this particular form. Zero form, although it was the form with high degree of reflecting power relationship, was applied as well in invitations under the feeling that invitation to a dinner out per se might compensate the nonuse of any other form. Using zero form when inviting the wife was justified by the act of invitation itself, which qualifies the zero form to reflect the affect/liking dimension.

To end this sub-section on AF's functions, analysis found direct relationship between language users and language practices that are indicative of shared identities. Identified functions of AFs in managing the relationship between spouses seems characteristic of rural husbands' language practices which reflect shared values, knowledge, beliefs and identity in rural Jordanian areas. Similar to Giles, Bourhis and Taylor (1977:322) who emphasized adjusting the choice of style by language user's values to fit attitudes and intentions towards others, husbands in this study showed being motivated chiefly by the situation to adjust and choose which AF to use so as to express values, attitudes and intentions towards wives, by such means expressed by Wood and Kroger (1991:145) as 
establishing the relative social meanings such as power and distance of speaker and hearer.

\section{Summary, conclusions and recommendations}

Despite the universality of the notion of using AFs, the elements that make them up, the rules that govern their use and the functions thereof are believed to be culture, context and society dependent. This four-fold study has aimed at investigating the most persistent AFs employed in rural Jordanian community as used by husbands, some social factors that may have impact on use, and the functions of AFs in various situational contexts, and thus the influence of situation (namely, speech situation and speech act) on use. Focus was on the use of AFs as an entry point into complaint, invitation, greeting and request.

I have provided a detailed analysis of the AFs which are employed by Jordanian husbands in rural areas. Results showed that Jordanian husbands in rural communities use conventional modes of addressing as part of the socialization process with their wives, modes that mirror the nature of the relation between spouses and attitude of husbands towards the wife in such communities. Husbands use five persistent categories: zero form, teknonymy, epithets, forenames and endearment terms. Results indicated describing rural husbands as smart people who creatively use AFs in a socio-cultural context that depict a stereotypic cautious users of AFs.

This study supports Hymes' (1972) argument about the role of situated data of speakers' 'communicative choices and their interpretation of their choices in enhancing our understanding of the distinctive and complex systems' of spousal daily interactions in rural communities. It has also supported Holmes' (1992) pointing to the magnitude of information one can get from studying how language works in a community. This study has emphasized Fitch's (1991) as well as Hymes' (1972) point on the significance of studying the socio-cultural background of the group or community under study, a significance that has showed its value on the discovery of the meanings and functions of AFs shared by a particular group of people. The study has highlighted that AFs used by Jordanian rural husbands are fluid in terms of function which mainly serves in spouse role designation and affective effect. Although husbands used similar forms, the same resources appeared to be used for various functions. They designate roles for the speaker and addressee, set the tone for a speech act, control interaction, and establish, emphasize or maintain the relative politeness, power, solidarity, status and intimacy which explicate a culturally distinct system of meanings. The study therefore enhances our knowledge of the link between society, culture and communication. The identified functions were much situation-governed. AFs have been found as mostly 'stereotypic social indexical' (using Agha's (2007) term), and there appeared to have major elements affecting the husband-to-wife choice of $\mathrm{AF}$ and functions of AFs: the speech event and speech act, the normative roles, rights and 


\section{A Sociolinguistic Study of Husband-to-Wife Address Forms and Functions \\ in Rural Jordanian Community}

obligations of the relationship between the speaker and the listener.

Nevertheless, other social variables showed insignificant impact, with except for the educational background of spouses and 'the how long' they have been married which showed significant impact. The higher the academic level of the husband, the more linguistic resources he employed. In addition, the higher the educational level of the wife, the more varied AFs husbands tend to employ for varied functions in different situations. This attitude of educated husbands towards the wives with higher education could be interpreted as follows: the more educated people are, the more likely than others they recognize the various roles of interactants, the familial values, the interpersonal and social constraints, and the situation requirements. Results showed that the more the years spent in marriage, the fewer the used varieties of AFs become and the more distancing and less affectionate function of AFs is intended to convey.

These idiosyncratic use and functions of AFs in rural communities could be generally attributed to the rural husbands' sharing of the same socio-cultural background, and thus shared practices, values, knowledge, beliefs, attitudes and identity. The study, therefore, supports the view on the influence of society and culture on language use, as well as how language is sensitive to situational context. AFs in spouse interaction reflected uniqueness of Jordanian culture and a practical value in managing spouse relationships in rural settings. This study has supported Hymes' (1972) value of examining the social meaning of particular communicative choices in relation to those who make them. Jordanian spouses' interaction do not only reflect the uniqueness of their culture, but also show the practical value of the AFs in managing human relationships in rural settings in line with what speakers consider it suitable to their socio-cultural context.

Despite being limited to a relatively small number of participants, this study proposes the following recommendations. First, it is recommended that further study be done to identify other factors that may affect the choice of AFs and functions in this particular milieu. A second recommendation is to continue to track the husbands' AFs in urban communities. Third, investigating AFs used by wives to address husbands in rural Jordanian communities and form functions is also encouraged. A final recommendation is to disseminate the information gleaned from this study to studies concerned with other AFs as well as some pedagogic materials specially designed for non-native Arabic learners.

\section{References}

Afful, J. 2006. Address terms among university students in Ghana: The case of descriptive phrases [J]. The International Journal of Society and Culture, 20 (5): 1-6.

Afzali, K. 2011. The address terms of spouses in different social strata in Iran and its sociolinguistic implications [J]. International Journal of Linguistics, 3 (1):10.

Agha, A. 2007. Language and Social Relations [M]. Cambridge: Cambridge University Press. 


\section{Awni Shati M. Etaywe}

Aliakbari, M. and Toni, A. 2008. The realization of address terms in modern Persian in Iran: A socio linguistic study [J]. Linguistik Online, 35 (3): 3-12.

Brown, G. and Yule, G. 1989. Discourse Analysis [M]. Cambridge: Cambridge University Press.

Brown, P. and Levinson, S. 1987. Politeness: Some Universals in Language Usage. Studies in Interactional Sociolinguistics [M]. New York: Cambridge University Press.

Brown, R. and Ford, M. 1961. Address in American English [J]. Journal of Abnormal and Social Psychology, 62: 375-85.

Brown, R. and Gilman, A. 1960. Pronouns of Power and Solidarity [A], in P. Giglioli (ed.), Language and Social Context [C]. London: Cox and Wyman. 252-282.

Buss, S. 1999. Appearing respectful: The moral significance of manners [J]. Ethics, 109 (4): 795-826.

Cameron, D. 1992. Feminism and Linguistic Theory [M]. New York: Palgrave Publishers.

Chaika, E. 1982. Language: The Social Mirror. Newbury House Publications [M]. Rowley, MA: Newbury House.

Ervin-Tripp, S. 1972. On Sociolinguistic Rules: Alternation and Co-occurrence. Directions in Sociolinguistics [J]. The Economic Journal of Takasaki City University of Economics, 45 (1): 71-94.

Farghal, M. Shakir, A. 1994. Kin terms and titles of address as relational social honorifics in Jordan Arabic [J]. Journal of Anthropological Linguistics, 36 (2): 240-253.

Fasold, R. 1990. Sociolinguistics of Language [M]. Oxford: Blackwell.

Fitch, K. 1991. The interplay of linguistic universals and cultural knowledge in personal address: Colombian Madre terms [J]. Communication Monograph, 58: 254-272.

Friedrich, P. 1972. Social context and semantic future: The Russian pronominal usage [A], in J. Gumperz and D. Hymes (eds.), Direction in Sociolinguistics: The Ethnography of Communication [C]. New York: Holt, Rinehart and Winston. 407-434.

Giles, H., Bourhis, R. and Taylor, D. 1977. Towards a theory of language and ethnic group relations [A], in H. Giles (ed.). Language, Ethnicity and Intergroup Relations: European Monographs in Social Psychology [C]. London: Academic Press. 307-348.

Goodenough, W. 1965. Rethinking "status" and "role": toward a general model of the cultural organization of social relationships [A], in Banton M. (ed.) The Relevance of Models for Social Anthropology Monographs [C]. London: Tavistock.

Goyvaerts, D. 1972. Linguistic behaviour and the acquisition of social roles: one aspect of linguistic performance [J]. Studia Linguistica, 26 (1): 1-13.

Holmes, J. 1992. An Introduction to Linguistics [M]. London: Longman.

Holmes, J. 1995. An Introduction to Sociolinguistics: Learning About Language [M]. London: Longman.

Hudson, R. 2001. Sociolinguistics [M]. Cambridge: Cambridge University Press.

Hymes, D. 1962. The ethnography of speaking [A], in T. Gladwin and W. Sturtevant (eds.), Anthropology and Human Behaviour [C]. Washington, DC: Anthropological Society of Washington. 13-53.

Hymes, D. 1964. Modes of Address, Language in Culture and Society: A Reader in Linguistics and Anthropology [M]. NY: Harper and Row.

Hymes, D. 1972. Editorial introduction [J]. Language in Society, 1: 1-14

Keshavarz, H. 2001. The role of social context, intimacy, and distance in the choice of forms of address [J]. International Journal Social Language, 148: 5-18.

Labov, W. 1972. Sociolinguistic patterns [M]. Chap. 3, The isolation of contextual styles (70-100); Chap. 5, Hypercorrection by the lower middle class as a factor in linguistic change (122-142). Philadelphia: University of Pennsylvania Press.

Levinson, S. 1983. Pragmatics [M]. Cambridge: Cambridge University Press.

Masson, L. 2001. Ask an expert: Explaining the etiquette effect [J]. CA Magazine, 134 (3): 18.

Mehrotra, R. 1985. Sociolinguistics in Hindi Contexts: Contributions to the Sociology of Language [M]. New York: Mouton de Gruyter.

Okamura. A. 2002. How do English speakers address their Japanese colleagues?[J]. Multilingua, 28: 355377.

Owen, L. 1995. The role of teachers' education in nurturing honorable and principled teaching [J]. Educational Horizons, 74: 43-48. 


\section{A Sociolinguistic Study of Husband-to-Wife Address Forms and Functions in Rural Jordanian Community}

Oyetade, S. 1995. A sociolinguistic Analysis of address terms in Yoruba [J]. Journal of Language and Society, 24: 515-53.

Parkinson, D. 1985. Constructing the Social Context of Communication: Terms of Address in Egyptian Arabic [M]. Berlin: Mouton de Gruyter.

Philipsen, G. 1975. Speaking "like a man" in Teamsterville: Culture patterns of role enactment in an urban neighborhood [J]. Quarterly Journal of Speech. 61 (1): 13-22. doi:10.1080/00335637509383264.

Philipsen, G. and Huspek, M. 1985. A Bibliography of Sociolinguistic Studies of Personal Address [J]. Anthropological Linguistics, 27 (1): 94-101.

Ruhlemann, C. 2007. Conversation in Context [M]. London: Continuum.

Saville-Troike, M. 1997. The Ethnographic Analysis of Communicative Events [A], in N. Coupland and A. Jaworski (eds.), Sociolinguistics [C]. London: Macmillan press Ltd. 126-145.

Taavitsainen, I. and Jucker, H. 2003. Diachronic Perspective on Address Term Systems [M]. Philadelphia: John Benjamins North America.

Thome-Williams, A. 2004. Sociolinguistic aspects of forms of address in Portugal and Brazil: Tu or Voce?[J]. Intercultural Communication Studies, 13 (3): 85-99.

Wang, J. 2003. A Comparative Analysis for Sino-English Appellation of Social Intercourse [J]. Journal of Harbin University, 8: 48-50.

Watts, R. 2005. Linguiostic politeness research: Que vadis?[A] In R. Watts, S. Ide and K. Ehlich (eds.), Politeness in Language: Studies in its History and Practices [C]. xi-xivii. Berlin, New York: Mouton de Gruyter.

Wierzbicka, A. 2010. Experience, Evidence, and Sense: The Hidden Cultural Legacy of English [M]. Oxford: Oxford University Press.

Winchatz, M. 2001. Social meanings in social interactions: An ethnographic analysis of the second person pronoun Sie' [J]. Research on Language and Social Interaction, 34 (3): 337-369.

Wood, L. and Kroger, R. 1991. Politeness and forms of address [J]. Journal of Language and Social Psychology, 3: 145-68.

World Bank. 2015. Collection of development indicators [OL]. Retrieved from Jordan - Rural population https://tradingeconomics.com/jordan/rural-population-wb-data.html.

Yang, C. 2010. Translation of English and Chinese addressing terms forms the cultural aspect [J]. Journal of Language Teaching And Research, 1 (5): 738-742.

Yang, X. 2010. Address terms of English: rules and variations [J]. Journal of Language Teaching and Research, 1 (5): 743-745. Academy Publisher: Finland. doi:10.4304/j1tr.1.5.

Yule, G. 2006. The Study of Language [M]. Cambridge: Cambridge University Press.

\section{Appendix (1): Discourse Completion Test}

Dear participant,

You are kindly requested to respond to the items of this questionnaire. The purpose of this questionnaire is to collect information about the various address forms (words and expressions) you may use when addressing your wife. This is to investigate the most persistent address forms, their functions and any variations (if any). The data you provide will be kept confidential and only used for the purpose of academic research.

\section{Part one: Please, provide the following personal information}

Thank you!
Gender:
$\square$ Male
Age:
$\square$ 24-34 $\square$ 35-45
Level of education: $\quad \square$ Tawjihi/Secondary school certificate
Place of residence: Village ..Governorate/city
$\square \mathrm{BA}$ and higher
How long have you been married (in years)? $\square$ 1-5 years $\square$ 6-10 years $\square$ 10+ Is your wife older or younger than you? $\square$ Older $\square$ Younger Is your wife's educational level similar to, higher/ lower than yours?
$\square$ similar
$\square$ lower
higher 


\section{Part two: Answer the following questions reflecting your typical behaviour}

1. What is the address form you usually use to address your wife when at home and alone?

2. What is the address form you usually use to address your wife when outside or at the presence of people other than your children?

Part three: The following are some situations you may find yourself in. Write your response as natural you would behave as possible.

1. You are alone in your room preparing yourself for an official business meeting for which you asked your wife to press your suit. You call her to bring you the suit. You find out that she has forgotten to iron it. You start complaining by addressing her:

Address form:

Why do you select this particular form (function)?

2. You are in the bedroom, at the presence of your brother, preparing yourself for an official business meeting for which you asked your wife to press your suit. You call her to bring you the suit. You find out that she has forgotten to iron it. You start complaining by addressing her:

Address form:

Why do you select this particular form (function)?

3. You are home, at the presence of your wife's sister, preparing yourself for an official business meeting for which you asked your wife to press your suit. You call her to bring you the suit. You find out that she has forgotten to iron it. You start complaining by addressing her:

Address form:

Why do you select this particular form (function):

4. Today is Eid al-Fitr (Ramadan Eid). While your children are playing in the backyard you want to greet your wife and congratulate her on being together on that special day. You initiate greeting by addressing her:

Address form:

Why do you select this particular form (function)?

5. Today is Eid al-Fitr (Ramadan Eid). During your mother's visit to you, you want to greet your wife and congratulate her on being together on that special day. You initiate greeting by addressing her: Address form:

Why do you select this particular form (function)?

6. Today is Eid al-Fitr (Ramadan Eid). During your wife's mother visit to you, you want to greet your wife and congratulate her on being together on that special day. You initiate greeting by addressing her: Address form:

Why do you select this particular form (function)?

7. Today is your wedding anniversary. You want to invite your wife to a dinner out. You start your invitation by addressing her:

Address form:

Why do you select this particular form (function)?

8. Today is your wedding anniversary. You want to invite your wife, before your mother, to a dinner out. You start your invitation by addressing her:

Address form:

Why do you select this particular form (function)?

9. Today is your wedding anniversary. You want to invite your wife, before your wife's mother, to a dinner out. You start your invitation by addressing her:

Address form:

Why do you select this particular form (function)? 


\section{A Sociolinguistic Study of Husband-to-Wife Address Forms and Functions in Rural Jordanian Community}

10. Your wife has received from you precious dowry as a condition to your marriage, and has recently inherited some money from her father. You want to ask her a financial help to buy a car. You start your request by addressing her:

Address form:

Why do you select this particular form (function)?

11. Your wife has received from you precious dowry as a condition to your marriage, and has recently inherited some money from her father. While sitting with your parents and siblings, you want to ask her financial help to buy a car. You start your request by addressing her:

Address form:

Why do you select this particular form (function)?

12. Your wife has received from you precious dowry as a condition to your marriage, and has recently inherited some money from her father. While sitting with her family, you want to ask her financial help to buy a car. You start your request by addressing her:

Address form:

Why do you select this particular form (function)? 